\title{
Simulation of the pump-battery power supply control system based on the unloading machine
}

\author{
Alexander Rybak $^{1, *}$, I Tsibriy ${ }^{1}$ \\ ${ }^{1}$ Don State Technical University, 1, pl. Gagarina, 344002, Rostov-on-Don, Russia
}

\begin{abstract}
The aim of this article is to create a control system for a constant hydraulic power source pressure, a pump -battery power source equipped with an original design of the hydraulic pump discharge machine that provides relay switching of its operation mode. This aim is achieved by using a simulation method based on the application of volumetric stiffness theory of hydraulic systems and their elements. As a result of a numerical experiment conducted by solving the equations that make up the mathematical model of power supply, its main technical characteristics and the influence of its main design parameters on its functional features and operational properties are obtained. The obtained results showed that by changing the various design parameters of unloading machine, it is possible not only to change the upper (maximum) and lower (minimum) values of the battery charging pressure, but also to adjust their difference depending on the requirements for the power source. The main result of this study is that as a result of a numerical experiment, it is proved that the unloading machine provides a clear relay switching of the pump operation mode from unloading to operating mode and Vice versa. The identified properties make a very promising use of a pump -battery power source in the hydraulic systems of mobile machines and process equipment.
\end{abstract}

\section{Introduction}

Problems of creating modern, reliable, high-quality and economical hydraulic drives have taken much attention these days. [3.6]. It should be noted that one of the most important elements of a hydraulic drive is its power source. Hydraulic power supplies used in modern technological equipment and mobile machinery, can be usually of two types - DC power supplies working fluid flow and sources of supply of constant pressure. Among the constant pressure supply sources most widely used sources of pump-storage hydraulic power works as follows. Working fluid from the flow source (pump) is supplied to the consumer, in which there is a hydraulic accumulator mounted inlet. When the consumer is working, it is powered by a rechargeable battery, wherein the fluid loss compensates for the pump and thus at the inlet to the consumer pressure always maintaines the same level - equal to the pressure in the accumulator. A drawback of such power supplies is that whenit does not work, the consumer battery recharging and opens the safety valve, which is lost, all the energy imparted by the working fluid pump. To prevent the relief valve so-called unloading valves are used [1],

\footnotetext{
*Corresponding author:2130373@mail.ru
} 
which are automatically opened, when the pressure at the pump outlet predetermined maximum (top) values, ensuring single mode operation.

\section{Statement of the Problem}

In this paper we describe the automatic control system power source of constant pressure, the hydraulic pump discharge machine equipped with a $[2,3]$, comprising a differential valve, which virtually eliminates the likelihood of occurrence of the work unloading machine in hover mode, providing a clear switching relay pump operation.

The article also provides information about the structure of the proposed discharge machine, its mathematical model and the results of studies conducted in the form of a numerical experiment.

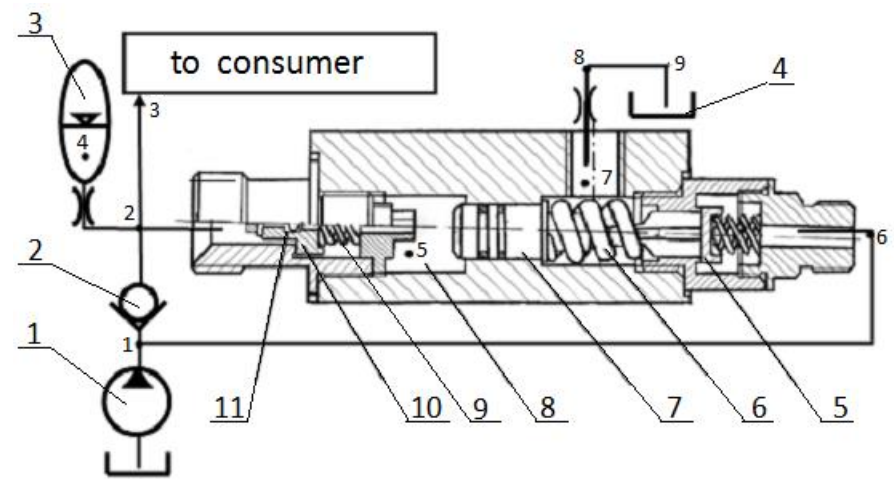

Fig. 1. The hydraulic-pump circuit of the battery power supply with automatic unloading.

Driving power source device proposed automatic discharge of the hydraulic pump, is shown in Figure 1. It operates as follows. The working fluid from the hydraulic pump 1 through the check valve 2 is sent to the consumer. If the feed pump is greater than the flow rate of the working fluid that is used by the consumer, its surpluses are sent to hydro accumulator 3, the pressure of which is increased. If the pressure at the inlet of the accumulator 3 (the pressure in point 2, the hydraulic system) exceeds the pressure setting valve controller 10 discharge machine, its gate will move to the right and a portion of the working fluid will travel to 8 unloading machine control chamber in which the pressure will increase, which will lead to the movement of the plunger 7 and the right opening of the drain line valve 5 unloading machine, hence the hydraulic fluid from the pump under pressure through a discharge channel 1-6-7-8-9 will go into the drain tank 4 - hydro pump is unloaded.

Checked valve 2 in this case will be closed and the power will be carried out only at the expense of the liquid in the accumulator 3 . The pressure in the accumulator 3 decreases, resulting in an outflow of hydraulic fluid through the check valve 11 from the control chamber 8 , and hence the shutter of the overflow valve 5 will be closed. The pump returns to the operating mode of functioning.

\section{Research method}

The dynamics of the pumping-source power of the battery equipped with the proposed discharge machine, may be represented by a system of differential equations describing the behavior of the various system components in the course of its transition from one steady state to another. To describe the operation of the hydraulic system of the considered power source to transient modes, we use the technique based on the use of the concept of volumetric 
stiffness of the hydraulic system [4 ... 14] which allows to carry out the calculation of the behavior of the drive system in real time, followed by analysis of its operational properties, identifying, at the same time, the influence of design features and technological features of the system to its properties [ $15 \ldots 18]$. The mathematical models developed using the theory of toughness volume considerably simplify and speed up the process of analyzing hydraulic actuators, what makes it possible to use in the design of "partial synthesis method" [19], which greatly simplifies the design process and improves its quality.

According to the theory of volume stiffness increment of pressure at any point in the hydraulic system during the transition process can be determined by the expression

$$
d p=C_{i}\left(\sum Q_{i . e n}-\sum Q_{i . e x}\right) \mathrm{dt}
$$

Where dt is increment divisions in the I point of the hydraulic system in $\mathrm{dt}$; Ci- reduced coefficient of volumetric stiffness considered elementary system volume, $\Sigma$ Qi.еп и $\Sigma$ Qi.exaccordingly, the amount of working fluid costs included in the reporting scope and coming out of it. In this case, the speaker system of the hydraulic pump, a battery pack shown in Figure 1, will have the form:

$$
\begin{gathered}
d p_{1}=C_{1}\left(Q_{p}-Q_{c v 1}-Q_{1-6}\right) d t \\
d p_{2}=C_{2}\left(Q_{c v 1}+Q_{c v 2}-Q_{a c}-Q_{2-3}-Q_{2-5}\right) d t \\
d p_{3}=C_{3}\left(Q_{2-3}-Q_{c o n s}\right) d t \\
d p_{4}=C_{4} Q_{a c} d t \\
d p_{5}=C_{5}\left(Q_{2-5}-Q_{c v 2}-Q_{p l}\right) d t \\
d p_{6}=C_{6}\left(Q_{1-6}-Q_{6-7}\right) d t \\
d p_{7}=C_{7}\left(Q_{6-7}-Q_{7-8}+Q_{p l}\right) d t \\
d p_{8}=C_{8}\left(Q_{7-8}-Q_{8-9}\right) d t
\end{gathered}
$$

Where:

$\mathrm{dp}_{1} \ldots \mathrm{dp}_{8-}$ pressure increment at the appropriate points of the hydraulic power supply system during dt;

$\mathrm{C}_{1} \ldots \mathrm{C}_{8}$ - reduced coefficients of volumetric stiffness in points sponding hydraulic power supply system;

$\mathrm{Q}_{\mathrm{p}-\text { hydro actual feed pump; }}$

$\mathrm{Q}_{\mathrm{cv1}}$ и $\mathrm{Q}_{\mathrm{cv2}}$ - Working fluid flow through the check valve 2 and the check valve 11, respectively;

Qac- Working fluid consumption, aimed at filling the hydro accumulator 3;

$\mathrm{Q}_{1-6}, \mathrm{Q}_{2-3}, \mathrm{Q}_{2-5}, \mathrm{Q}_{6-7}, \mathrm{Q}_{7-8}$, and $\mathrm{Q}_{8-9}$ - costs of working fluid at respective portions of the hydraulic power supply system;

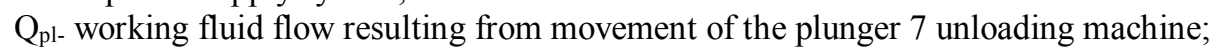

Q cons- working fluid flow withdrawn from the supply by the consumer.

\section{The results of the numerical experiment}

In order to identify the basic functionality of the pump-battery power source of the hydraulic control system equipped with an automatic unloading pump of the proposed design has been carried out a numerical experiment. The experiment has both a numerical solution to the 
above mathematical model of the power supply and the use of SimInTech mathematical package. In the course of the experiment revealed the effect of various design parameters of the machine unloading pump and functional parameters of the power supply system as a whole in its dynamic properties.

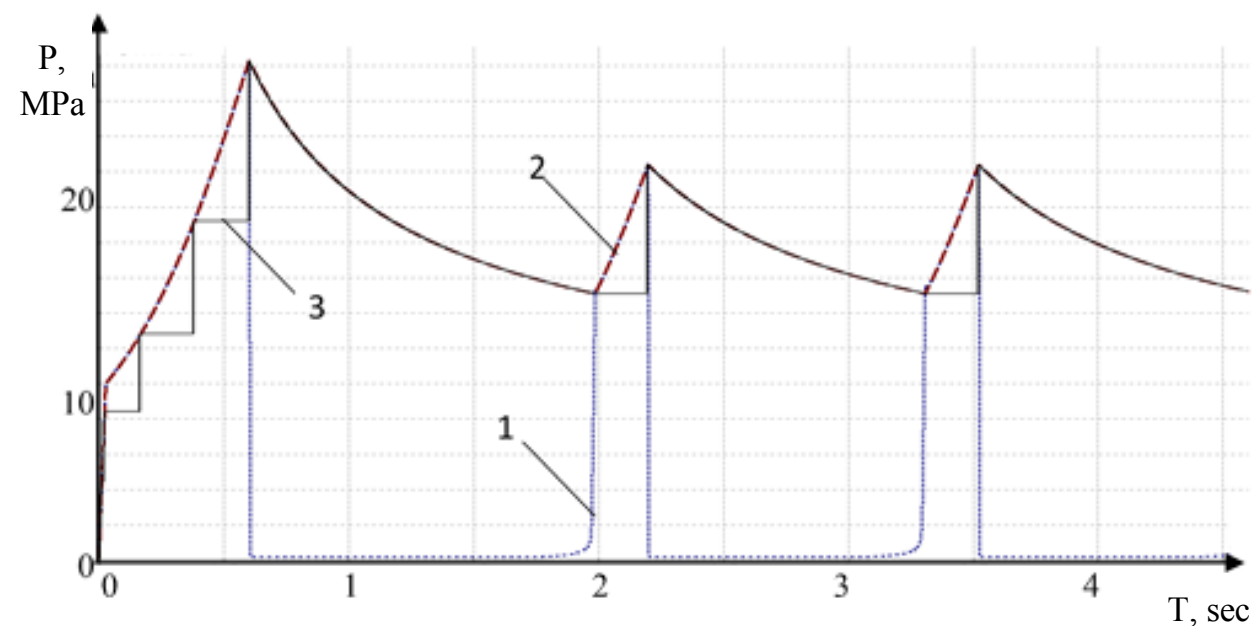

Fig. 2. Changes in pressure at various points in time the hydraulic power source 1 - the output of the hydraulic pump; 2 - accumulator; 3 - in the control chamber discharge machine.

The Figure 2 shows an example of characteristics of the pump-battery power supply obtained by carrying out a numerical experiment. From these graphs it is seen that during the first start-up (time less than 1 second) occurs stepwise increasing pressure in discharge machine control chamber 8 to a working level, after which the machine is operating normally.

\section{The discussion of the results}

The results showed that the functional properties of the power supply, equipped with a discharge machine, the most significant influence recompression force of the working spring 6 , the outer diameter of the shutter controller 10 and the value of the diameter of the plunger 7. In this case, the change of the spring pre-compression force of the plunger 6 and the magnitude of the diameter of 7 leads to changes in the magnitudes of the upper automaton triggering discharge pressure and a difference of upper and lower opening pressure.

\section{Conclusion}

Thus, the proposed design of the machine discharge pump provides pump-work hydraulic drive battery power supply in a given mode with high accuracy on and off for given values of the upper and lower pressures. In order to set the interval triggering automatic discharge and the magnitude of the upper (lower) opening pressure is most convenient to use the setting of pre-compression force of the spring 6 and the regulator valve spring 9 that can be set during assembly, or to create a regulator design with the possibility of regulation of said forces during the operation of the automaton unloading.

\section{References}


1. Y. Sang, W. Sun, F. Duan, J. Zhao, Mechatronics 62,102254 (2019)

2. A.N. Sova, V.I. Polyanskiy, M.I. Stepanov, S.N. Shevchnko, G.S. Mazlumyan, Dual technology 4(81), 68-71 (2017)

3. A.I. Ozerskiy, N.A. Tseligorov, E.V. Nasyrina, 14th International Scientific-Technical Conference on Actual Problems of Electronic Instrument Engineering APEIE, 332-335 (2018)

4. I. Chetverikova, P. Popikov, IOP Conference Series: Earth and Environmental Science 392(1), 012067 (2019)

5. M.V. Drapalyuk, P.I. Popikov, R.V. Yudin, A.A. Fomin, R.V. Chernukhin: IOP Conference Series: Materials Science and Engineering 142(1), 012090 (2016)

6. V.S. Scherbakov, N.S. Galdin, I.A. Semenov, Construction and road vehicles 9, 37-41 (2019)

7. V.E. Shcherba, V.V. Shalai, V.N. Kostyukov, Chemical and Petroleum Engineering 54(5-6) (2019)

8. M.S. Koritov, V.S. Scherbakov, D.A. Ots, Construction and road vehicles 2, 26-32 (2019)

9. V.V. Sirkin, I.N. Kvasov, Y.F. Galuza, M.A Fedorov, Omsk scientific Vestnik. A series of Aviation and rocket and power engineering 2(4), 9-14 (2018)

10. V.V. Sirnik, V.R. Edigarov, V.A. Treer, Vestnik of machine building 7, 24-27 (2017)

11. A.M. Bazhenov, V.E. Shcherba, V.V. Shalai, A.V. Grigor'ev, Russian Engineering Research 39(5), 377-382 (2019)

12. V.S. Scherbakov, B.N. Galdin, Construction and road vehicles 7, 19-23 (2019)

13. M.S. Korytov, V.S. Shcherbakov, V.V. Titenko, D.A. Ots, Journal of Physics: Conference Series 1260(11), 112015 (2019)

14. V.E. Shcherba, V.S. Shcherbakov, N.S. Galdin, A.V. Grigor'ev, Chemical and Petroleum Engineering 54(3-4), 177-182 (2018)

15. A.T. Rybak, M.P. Shishkarev, A.A. Demyanov, V.P. Zharov, MATEC Web of Conferences 226, 01001 (2018)

16. A.T. Rybak, V.P. Zharov, A.V. Serdyukov, Russian Engineering Research 29(2), 194197 (2009)

17. A.T. Rybak, A.R. Temirkanov, O.V. Lyakhnitskaya, Russian Engineering Research 38(9), 702-704 (2018)

18. A.T. Rybak, I.K. Tsybriy, S.V. Nosachev, A.Y. Pelipenko, AIP Conference Proceedings 2188, 050042 (2019)

19. A.T. Rybak, A.Y. Pelipenko, M.P. Shishkarev, M.Y. Nevzorova, MATEC Web of Conferences 226, 01017 (2018)

20. S.V. Nosachev, A.A. Abalov, V.P. Zharov, V.A. Minko, MATEC Web of Conferences 226(7), 04003 (2018)

21. B.A. Kartashov, O.S. Kozlov, E.A. Shabaev, Dynamic modeling environment for SimInTech technical systems (DMK-Press, Moscow, 2017) 